\title{
GESTÃO DA AVALIAÇÃO DE APRENDIZAGEM: UMA ANÁLISE SOBRE O CURSO DE ADMINISTRAÇÃO DO CEDERJ - POLO DE ITAPERUNA
}

\author{
Rodrigo Anido Lira | rodrigoanidolira@gmail.com \\ Doutorado em Sociologia Política pela Universidade Estadual do Norte Fluminense Darcy Ribeiro (UENF). Professor da Sociedade Bra- \\ sileira de Instrução ( UCAM), com experiência nas áreas de Pessoas, Marketing, Planejamento e Estratégia. \\ Cristiano Souza Marins | csm@metal.eeimur.uff.br \\ Mestrado em Engenharia de Produção pela Universidade Estadual do Norte Fluminense Darcy Ribeiro ( UENF) e, doutorando em En- \\ genharia de Transporte no PET/COPPE/UFRJ. Professor da Universidade Federal Fluminense ( UFF), no Polo Universitário de Campos \\ dos Goytacazes-RJ.
}

Edson Terra Azevedo Filho | etaf@uenf.br

Mestrado em Engenharia de Produção pela Universidade Estadual do Norte Fluminense Darcy Ribeiro ( UENF) e Doutorando em Sociologia Política pela UENF.

\section{Resumo}

A proposta deste trabalho foi investigar o modelo de gestão da avaliação da aprendizagem adotado pelo Consórcio Centro de Educação Superior a Distância do Estado do Rio de Janeiro - CEDERJ, visando verificar se atende aos preceitos norteadores estabelecidos pelo Ministério da Educação, por meio dos Referenciais de Qualidade para Educação Superior a Distância. Para o atendimento desse objetivo, utilizou-se como metodologia, inicialmente, a revisão bibliográfica sobre o tema corrente. Posteriormente foram realizadas entrevistas com tutores presenciais e com o coordenador do curso de Administração do CEDERJ do Polo de Itaperuna, visando analisar as práticas da instituição em relação à gestão da avaliação da aprendizagem. A partir da coleta de dados foi utilizado o método de análise de conteúdo, de modo a verificar a aderência do modelo estudado ao referencial teórico. A partir da análise dos resultados da pesquisa, à luz da metodologia adotada, pôde-se constatar que o modelo estudado efetivamente se enquadra nas diretrizes adotadas como referencial. Apesar disso, visando contribuir com a melhora constante dos aspectos relacionados à Educação a Distância (EaD), este trabalho sugere algumas adequações para tornar o modelo em questão ainda mais eficiente.

\section{Palavras-chave}

Educação a distância (EaD). Gestão da avaliação da aprendizagem. CEDERJ. Ensino de Administração. 


\section{Learning assessment management: an analysis of the CEDERJ administration course - Itaperuna Pole}

\section{Abstract}

The purpose of this study was to investigate the learning assessment management model adopted by the Centro de Educação Superior a Distância do Estado do Rio de Janeiro - CEDERJ, to verify whether it meets the guiding principles established by the Ministry of Education through the Quality Benchmarks for Distance Higher Education. In order to meet this goal, it was used as a methodology, initially, the literature review on the current theme and later interviews were conducted with presence tutors and the coordinator tutor of the CEDERJ Administration course in Itaperuna Pole, in order to examine the practices of this institution concerned its learning assessment management. From the data collection method was used content analysis to verify the adherence of the studied model in relation to the theoretical framework. From the analysis of survey results in light of the methodology adopted, it was found that the studied model effectively fits the guidelines adopted as a reference. Nevertheless, in order to contribute to constant improvement of aspects related to Distance Education (DE), this paper suggests some adjustments to become the model in question even more efficient.

\section{Keywords}

Distance Education (DE). Learning assessment management. CEDERJ. Management education.

\section{Considerações iniciais}

Em função de sua importância e crescimento, torna-se relevante abrir um leque de discussóes sobre os modelos de gestão acadêmica adotados pelos cursos baseados em Educação a Distância (EaD).
A proposta deste trabalho consiste na contribuição resultante da análise do processo de gestão da avaliação da aprendizagem.

A gestão de processos está relacionada à "aplicação de técnicas, conhecimento e habilidades para garantir que um projeto tenha sucesso" (CARNEIRO; SANTOS, 2009, p. 3). Essa concepção orienta a construção deste estudo, visando estabelecer resultados esperados por processos (REPs) relacionados à avaliação da aprendizagem, especificamente do processo de gestão acadêmica do Consórcio CEDERJ/ Fundação CECIERJ.

Buscando suporte nos Referenciais de Qualidade para Educação Superior a Distância (2007, p. 20), criados pelo Ministério da Educação, foi constatado que estes preveem, entre outras, que o professor deve ter a capacidade de "realizar a gestão acadêmica do processo de ensino-aprendizagem, em particular motivar, orientar, acompanhar e avaliar os estudantes". Assim, parte-se da premissa de que a análise dos processos de gestão acadêmica $e$ a identificação de seus respectivos REPs possibilitam aos gestores o desenvolvimento de ferramentas que podem contribuir para o sucesso do modelo de gestão em questão.

Neste trabalho, objetivou-se estudar o processo de gestão acadêmica relacionado à avaliação da aprendizagem utilizado pelo CEDERJ, identificando seus REPs e, assim, efetuando uma análise comparativa visando verificar a aderência do modelo estudado, tanto em relação à legislação vigente quanto ao referencial teórico adotado.

A estrutura deste trabalho é composta por esta introdução, seguida pelo referencial teórico que trata dos referenciais de qualidade, dos processos de gestão acadêmica em EaD e do estabelecimento dos REPs. A Seção 3 aborda os procedimentos metodológicos utilizados e é seguida pela apresentação e discussão dos resultados obtidos mediante pesquisa. As últimas seções referem-se às considerações finais e às referências adotadas. 


\section{Referencial teórico}

\subsection{Referenciais de Qualidade da SEED/MEC}

Considerando a proposta do governo brasileiro de criação de políticas públicas voltadas à expansão do ensino superior no Brasil, entre as ações propostas pelo MEC (Ministério da Educação) destaca-se a EaD como importante ferramenta de disseminação da educação de qualidade para todo o território nacional.

De forma a criar uma secretaria específica para tratar de assuntos relacionados à $\mathrm{EaD}$, em 1996 foi criada a SEED (Secretaria de Educação a Distância). Em função da forte expansão dos cursos baseados na EaD, a SEED em 2007 lançou os Referenciais da Qualidade para a Modalidade de Educação Superior a Distância, com o objetivo de balizar a implementação de cursos em EaD, visando ao estabelecimento e a manutenção do nível de qualidade desses cursos.

De acordo com o documento, em função da complexidade para estabelecer referenciais de qualidade para cursos superiores na modalidade $\mathrm{EaD}$, deveriam ser abordados aspectos "pedagógicos, de recursos humanos e infraestrutura" (SEED/MEC, 2007). Assim, podem ser citados como os principais tópicos abordados no referido documentos os seguintes:

(i) Concepção de educação e currículo no processo de ensino e aprendizagem; (ii) Sistemas de comunicação; (iii) Material didático; (iv) Avaliação; (v) Equipe multidisciplinar; (vi) Infraestrutura de apoio; (vii) Gestão acadêmicoadministrativa; (viii) Sustentabilidade financeira (SEED/ MEC, 2007, p. 8).

De acordo com os Referenciais da Qualidade, tendo como referência a EaD, o modelo de avaliação da aprendizagem "deve ajudar o aluno a desenvolver graus mais complexos de competências cognitivas, habilidades $e$ atitudes, possibilitando-lhe alcançar os objetivos propostos" (SEED/MEC, 2007).

Dentre os tópicos apresentados, foi eleito o item sobre avaliação para servir de parâmetro para a análise de práticas acadêmicas em EaD. Neste, são con- templadas a avaliação de aprendizagem e a avaliação institucional. No caso específico deste trabalho será utilizada como balizadora a parte referente à avaliação de aprendizagem.

\subsection{Gestão da avaliação da aprendizagem em $E a D$}

A avaliação do discente é fundamental ao processo educacional, pois, além de possibilitar o aferimento do impacto do ensino sobre a aprendizagem, proporciona ao docente a oportunidade de acompanhamento do desempenho da turma e a oportunidade para a reflexão sobre o desempenho de seu trabalho. Pela avaliação é possível comparar os objetivos propostos aos resultados obtidos e, dessa forma, analisar o progresso $e$ as dificuldades do trabalho docente (BARBOSA, 2008; MORETTO, 2008; TARDIFF; LESSARD, 2008). Segundo Libâneo (1994, p. 196), a avaliação é um elemento do processo educacional que visa, "através da verificação e qualificação dos resultados obtidos, determinar a correspondência destes com os objetivos propostos e, daí, orientar a tomada de decisões em relação às atividades didáticas seguintes".

Porém, apesar de sua importância, a avaliação sofre muitos problemas que a impedem de desempenhar seu verdadeiro papel. Desde a visão punitiva que os alunos cultivam já nos primeiros anos de estudo até problemas como falta de interesse dos mesmos em relação ao aprendizado, falta de estrutura adequada, baixa remuneração dos professores (SINDER, 2010).

Por isso, a avaliação deve ser encarada pelos profissionais envolvidos como um aspecto desafiador dentro do contexto do processo de aprendizagem, já que ela deve ser concebida na prática como medida de sucesso desse processo. Portanto, percebe-se que efetuar uma análise mais aprofundada acerca da avaliação da aprendizagem torna-se fundamental em função de sua importância para o processo educacional, tendo como função servir como diagnóstico, propiciar a autocompreensão e motivar o conhecimento e a aprendizagem (BRAGANÇA, 2010). 
A Educação a Distância é um processo de ensino-aprendizagem mediado por tecnologias no qual docentes e discentes estão separados espacial e/ou temporalmente (MORAN, 2008). A partir da análise dos levantamentos das atividades das práticas docentes realizadas por Tardiff e Lessard (2008) e Peters (2006) a respeito da educação presencial e a distância, respectivamente, têm-se evidências da diferenciação que deve existir entre essas duas modalidades.

No ensino presencial, as atividades contempladas na prática docente devem ser: planejamento, ensino e avaliação. $\mathrm{Na} \mathrm{EaD} \mathrm{são} \mathrm{contempladas,} \mathrm{além}$ das atividades citadas, outras duas, configurando da seguinte forma a ordem das atividades: planejamento, desenvolvimento e distribuição do material didático, exposição (ensino), avaliação e assistência (tutoria). Portanto, percebem-se claramente as diferenças que devem ser consideradas no desenvolvimento da EaD.

É importante notar que, apesar da grande semelhança com o ensino presencial, o processo de ensino-aprendizagem utilizado na $\mathrm{EaD}$ deve se diferenciar, a fim de conseguir suprir as carências do contato direto com os professores e alunos, além de outras práticas consagradas no ensino presencial (MORAN, 2008).

De acordo com Carvalho (2010), é necessária uma "nova pedagogia" para o ensino a distância que contemple eventuais obstáculos ao aprendizado e se adéque às expectativas tanto dos alunos que optam por essa modalidade de ensino quanto da sociedade em geral.

Conforme Campos et al (2007), Gusso (2009) e Quintana e Quintana (2012), a EaD possibilita uma avaliação contínua, que pode ser realizada de modo virtual ou presencial, de forma quantitativa e/ou qualitativa. Atualmente, com o avanço das tecnologias de informação e comunicação (TIC) e das ferramentas web 2.0, há inúmeras possibilidades de avaliação; os instrumentos mais utilizados entre as atividades de avaliação em $\mathrm{EaD}$ em ambientes virtuais são: chat, wiki, ferramentas de postagens de atividades (atividades online), portfólio, artigos, entrevistas, pesquisas etc. A avaliação presencial é realizada com provas, da mesma forma que ocorre em cursos presenciais.
2.3. Estabelecimento dos resultados esperados de processo (REPS)

Ao considerar a prática docente como um conjunto de processos que se integram para obter resultados esperados, é possível estabelecer REPs com o propósito de obter parâmetros de desempenho para a execução do referido processo (SILVA, 2009).

Foi considerada como base para o estabelecimento de REPs para o processo de Gestão da Avaliação da Aprendizagem em EaD a diretriz do SEED/MEC (2007), os Referenciais de Qualidade para a Educação Superior a Distância. Dessa forma, têm-se as seguintes orientações, que serão consideradas como REPs para o processo de gestão abordado:

O processo de avaliação deve possuir características formativas ${ }^{1}$ (ocorre durante todo o processo $e$ visa identificar o desenvolvimento do aluno) aliadas às somativas ${ }^{2}$ (ocorrem em momentos específicos do processo e visam atribuir notas);

- O processo de avaliação deve ser composto por avaliações a distância e avaliações presenciais; há obrigatoriedade e prevalência das avaliações presenciais;

- As avaliações devem ser cercadas de precauções para garantir a confiabilidade e a credibilidade dos resultados;

- Deve haver um claro planejamento de momentos presenciais obrigatórios, como atividades, estágios obrigatórios e avaliações, entre outros.

1 Ocorre durante todo o processo de ensino-aprendizagem e visa identificar o quê e quanto o discente domina um determinado conteúdo, bem como o quanto e o quê não foi dominado, para de tal modo auxiliar o docente e o discente a atingir os objetivos da disciplina, pela identificação das falhas e dos aspectos que precisam ser modificados para o domínio da disciplina (BLOOM; HASTINGS; MANDAUS, 1983).

2 O processo de avaliação somativa ocorre em momentos específicos do processo de aprendizagem $e$ visa à atribuição de notas de modo a fornecer ao aluno $e$ à sociedade um feedback a respeito do nível de aprendizagem alcançado. A avaliação somativa, apesar de ser a mais tradicionalmente utilizada pelas instituições de ensino, é também uma das mais criticadas, por colaborar com uma postura passiva do aluno em relação ao processo educacional (BLOOM; HASTINGS; MANDAUS, 1983). 


\section{Procedimentos metodológicos}

O objetivo principal deste trabalho consistiu em investigar o modelo de gestão da avaliação da aprendizagem adotado pela instituição analisada, visando verificar se ele atende aos preceitos norteadores estabelecidos pela SEED/MEC.

Para o atendimento do objetivo proposto pela pesquisa, foi utilizada inicialmente a pesquisa bibliográfica para o levantamento dos conceitos mais atuais relacionados à gestão da avaliação de aprendizagem na Educação a Distância e aos Referenciais de Qualidade para Educação Superior a Distância.

Posteriormente foi elaborado um questionário não estruturado baseado nos supracitados referenciais de qualidade que serviu como roteiro para a realização de entrevistas in loco com membros da equipe do curso de Administração do CEDERJ no polo de Itaperuna. Foram entrevistados o tutor coordenador do curso $e$ cinco tutores presenciais, fazendo o total de seis entrevistas (MALHOTRA, 2006). Os tutores presenciais entrevistados eram responsáveis pelas seguintes disciplinas: História do Pensamento Administrativo; Gestão de Marketing; Gestão de Pessoas; Gestão da Produção e Empreendedorismo.

A partir da realização das entrevistas, foi utilizado para a análise dos resultados o método de análise do conteúdo, que pode ser definido como:

Um conjunto de técnicas de análise das comunicações visando obter, por procedimentos sistemáticos e objetivos de descrição do conteúdo das mensagens, indicadores (quantitativos ou não) que permitam a inferência de conhecimentos relativos às condições de produção/recepção (variáveis inferidas) dessas mensagens (BARDIN, 1977, p. 42).

A utilização da análise de conteúdo é indicada para fins de verificação, visando confirmar ou não suposições preestabelecidas. Seguindo a proposta desse método, foram aplicados procedimentos interpretativos (qualitativos), confrontando os resultados obtidos com os indicadores propostos à investigação, buscando-se concluir se são ou não identificados no modelo de gestão da avaliação da aprendizagem adotado pelo CEDERJ os preceitos norteadores estabelecidos pela SEED/MEC (VERGARA, 2005).

\section{Apresentação e análise dos resultados}

Nesta seção do trabalho serão apresentados e analisados os resultados da pesquisa, iniciando-se com uma breve caracterização da unidade de análise.

\subsection{CEDERJ: apresentação da instituição}

Entre as políticas de expansão e democratização do ensino superior ocorridas no Brasil nesta última década, ocupa lugar de destaque a criação do Consórcio Centro de Educação Superior a Distância do Estado do Rio de Janeiro - CEDERJ, que hoje integra a Fundação Centro de Ciências e Educação Superior a Distância - CECIERJ. Trata-se de um exemplo de política pública voltada para área de Educação a Distância cuja criação ocorreu no ano de 2000 por meio da Secretaria de Estado de Ciência, Tecnologia e Inovação e que foi firmado entre as instituições públicas de Ensino Superior instaladas no estado: UFRJ, UERJ, UENF, UFF, UFRRJ e UNIRIO.

O objetivo do Consórcio CEDERJ é:

Atualmente são oferecidos quatorze cursos, e o suporte aos alunos do interior se dá nos 33 polos regionais, criados a partir de convênios com as prefeituras dos municípios-sede e que servem como referência de espaço físico para os alunos, já que a modalidade adotada é a semipresencial. 
4.2. Formas de avaliação utilizadas pelo CEDERJ no curso de Administração no Polo de Itaperuna - RJ

De acordo com o tutor coordenador entrevistado, o curso de Administração do CEDERJ é de responsabilidade da Universidade Federal Rural do Rio de Janeiro (UFRRJ).

Os cursos do CEDERJ possuem tutores presenciais e tutores a distância; tutores coordenadores de curso; professores coordenadores de disciplina $e$ o coordenador geral do curso. O papel dos tutores é ser um mediador entre o professor coordenador $e$ os alunos, oferecendo suporte à compreensão dos conteúdos apresentados para estudo. O tutor presencial está disponível para tutoria nos polos do CEDERJ, e os tutores a distância podem ser acessados pela plataforma $\mathrm{EaD}$ ou por telefone. $\mathrm{O}$ tutor coordenador do curso gerencia as atividades realizadas pelo seu curso no polo. Para cada disciplina dos cursos do CEDERJ há um professor coordenador, que deve pertencer a uma das universidades consorciadas; ele tem como função o planejamento, a coordenação dos tutores (presencial e a distância) e a elaboração das avaliações presenciais e a distância da sua respectiva disciplina. O coordenador geral de curso, que deve pertencer à universidade consorciada $e$ organizadora do curso, tem como responsabilidade desenvolver as atividades de planejamento e gestão das atividades desenvolvidas no curso em todos os polos e coordenar os professores coordenadores de disciplina $e$ os tutores coordenadores.

Após a exposição dos atores envolvidos no processo de aprendizagem, serão apresentadas as formas de avaliação utilizadas pelo CEDERJ no curso de Administração, especificamente no Polo de Itaperuna. Formalmente, existem três formas de avaliação: os exercícios avaliativos (EAs), as avaliações a distância (ADs) $e$ as avaliações presenciais (APs).

Os EAs, apesar de não terem nenhum peso de nota na avaliação, proporcionam ao aluno uma atividade de autoavaliação. Os EAs são apresentados aos alunos ao final de cada aula e unidade estudada, diretamente em seu material didático impresso. Esses exercícios possuem a função de evidenciar ao aluno como está seu nível de aprendizado em relação ao conteúdo estudado. Caso o estudante encontre dificuldades em resolver os exercícios propostos, é orientado a procurar o auxílio da tutoria (presencial e a distância) e a formar grupos de estudo com outros alunos.

As $\mathrm{ADs}$ representam $20 \%$ da nota do aluno e são importantes instrumentos de avaliação, tanto para o coordenador da disciplina conhecer como está o nível de desenvolvimento dos alunos quanto para o próprio aluno obter um feedback a respeito do seu nível de aprendizado. Podem ser citadas como tipos de $\mathrm{ADs}$ as atividades manuscritas que são entregues no Polo e a participação em fóruns de discussão e chats, entre outras. Um detalhe interessante é que, apesar de as $\mathrm{ADs}$ serem em sua maioria realizadas a distância, podem também contemplar atividades presenciais. Os entrevistados ressaltam que os cursos do CEDERJ são semipresenciais, isto é, apesar de a maioria das atividades serem realizadas a distância, há a obrigatoriedade da presença dos alunos em determinadas ocasiões, como avaliações presenciais e atividades acadêmicas realizadas no Polo.

As APs representam $80 \%$ da nota do aluno e são realizadas nos polos do CEDERJ, sendo obrigatória a presença dos estudantes. Essas avaliações são feitas pelos alunos de forma manuscrita e cercadas de muito rigor por parte dos tutores presenciais que as aplicam.

De acordo com os entrevistados, deveria ser mais estimulada por parte da coordenação geral dos cursos do CEDERJ a utilização formal de mais avaliações presenciais que visem desenvolver e avaliar não só as habilidades intelectuais, principalmente para o curso de Administração, que demanda a formação de alunos com grande desenvoltura nos relacionamentos interpessoais, trabalho em equipe e comunicação. Portanto, é importante que sejam propostas atividades que ofereçam aos alunos a oportunidade de vivenciar experiências específicas da sua formação.

4.3. Características das avaliações do curso de Administração do CEDERJ 
De acordo com o referencial teórico levantado para a realização deste trabalho, é recomendável que os processos de avaliação possuam características formativas aliadas às somativas. Dessa forma, os entrevistados informaram que as avaliações do CEDERJ são essencialmente somativas, pois há um processo sistemático de acompanhamento do desenvolvimento do aluno, ao mesmo tempo que se oferece retorno sobre seu desempenho.

Foi relatado que uma possível solução para esse problema seria envolver mais os tutores (presenciais e a distância) nesse processo, pois, apesar de os alunos serem orientados a procurar os tutores em caso de dúvida ou em busca de novas perspectivas sobre o assunto, essa procura é normalmente maior no início do curso, mas a partir do momento em que o aluno desenvolve maior autonomia e autodidatismo ao longo do curso, a procura se reduz de forma acentuada.

\subsection{Obrigatoriedade e prevalência das avaliações presenciais}

Além da importância de haver avaliações presenciais e a distância, uma importante recomendação presente nos Referenciais de Qualidade diz a respeito à obrigatoriedade e prevalência das avaliações presenciais em relação às avaliações a distância.

Com base nas informações coletadas, concluise que o CEDERJ acata as recomendações dos Referenciais em relação à obrigatoriedade das avaliações presenciais, já que possui tanto avaliações presenciais (APs e EAs) quanto a distância (ADs).

O CEDERJ também atende à recomendação da prevalência das avaliações a distância, pois, como citado, as avaliações presenciais representam $80 \%$ da nota do aluno, enquanto o valor das avaliações a distância é de apenas $20 \%$.

\subsection{Precauções para garantir a confiabilidade e credi-} bilidade do processo de avaliação

É recomendada a máxima precaução por parte da instituição em relação ao processo de gestão da avaliação, de modo a garantir plena confiabilidade $e$ credibilidade a ele. De acordo com os entrevistados, no CEDERJ esse processo é cercado de extremo rigor. Dentre os pontos considerados mais importantes para o atendimento dessa recomendação, podem ser citados:

- Existe grande controle sobre todos os prazos exigidos para a realização das avaliações. Desde o prazo para a entrega das $\mathrm{ADs}$ aos horários de início e términos das APs, o CEDERJ impõe seu cumprimento, criando efetivamente uma cultura de atendimento dos prazos predeterminados;

- Em relação à realização das $\mathrm{ADs}$, o aluno obtém acesso a elas diretamente pela plataforma virtual do CEDERJ e deve entregá-las de forma manuscrita no polo ou postá-la na plataforma até a data prevista;

- Para a realização das APs é montada uma grande estrutura. As avaliações chegam diretamente da coordenação central do CEDERJ em um envelope plástico lacrado no qual está expresso que ele não deve ser aberto caso existam indícios de que alguém tenha tentado abri-lo antes do prazo. São relacionados sempre pelo menos dois tutores presenciais para aplicar as APs em cada sala de aula. São escolhidos para aplicar as avaliações de um curso sempre tutores de outros cursos. Um aluno só pode ir ao banheiro acompanhado por um representante da instituição. Há um grande cuidado na conferência dos documentos de identificação quando os alunos assinam a lista de presença, para evitar qualquer fraude. Os dois últimos alunos que estiverem fazendo a avaliação devem ficar até que ambos terminem. Estes também devem acompanhar o fechamento da ata de prova e o lacre do envelope que contém todas as avaliações, que será enviado para a coordenação central para correção.

$\mathrm{Na}$ opinião dos entrevistados, o CEDERJ cumpre perfeitamente as recomendações a respeito da precaução em relação ao processo de avaliação, pois aplica as normas de segurança de forma bastante rígida. 
4.6. Planejamento dos momentos presenciais obrigatórios

De acordo com as entrevistas efetuadas, o CEDERJ atende perfeitamente às recomendações de planejamento dos momentos presenciais obrigatórios. Segundo os entrevistados, logo no início do semestre é disponibilizado aos alunos o calendário de avaliações de todo o período letivo. Normalmente os alunos podem ter acesso ao calendário diretamente na plataforma virtual do CEDERJ no Guia da Disciplina - que, de acordo com os entrevistados, é a "lei do curso" - ou mesmo nos polos, onde são fixados em murais específicos para esse fim.

Atividades como apresentações de TCCs e estágios obrigatórios acompanham o mesmo rigor de planejamento das avaliações. Em relação a outros momentos presenciais como palestras, debates e apresentações, há sempre a cobrança, por parte da coordenação, em relação aos tutores, para que eles sempre avisem com antecedência de pelo menos um mês caso agendem alguma atividade no polo, de modo que os alunos consigam se organizar e participar, já que normalmente essas atividades são marcadas aos sábados.

\subsection{Contribuições do modelo de gestão da avaliação} do CEDERJ para o desenvolvimento dos alunos e sugestões de melhoria para o modelo

De acordo com os entrevistados, o modelo de gestão da avaliação utilizado pelo CEDERJ contribui para o desenvolvimento dos alunos, pois, além de abranger todo o conteúdo das disciplinas ministradas, exige dos alunos grande capacidade de raciocínio e perspicácia. Segundo o coordenador, um dos fatores que podem ajudar a comprovar esta afirmação são os excelentes resultados obtidos pelos alunos do CEDERJ no Enade (Exame Nacional de Desempenho de Estudantes). Porém algumas considerações feitas a respeito do modelo merecem ser abordadas.

Inicialmente, o fato de o processo de avaliação do CEDERJ apresentar características mais somativas pode dificultar o desenvolvimento do aprendizado de alunos que possam ter dificuldade de aprendizagem ou até mesmo dificuldade de adaptação ao sistema baseado em EaD. Dessa forma, seria importante uma reestruturação principalmente no papel dos tutores (presenciais e a distância) para que passassem a oferecer maior suporte aos alunos, atribuindo dessa forma uma abordagem mais formativa ao modelo de avaliação, a partir de um acompanhamento mais personalizado dos alunos e do oferecimento de um feedback mais intenso a respeito do desempenho dos estudantes.

Outro fator que deve ser considerado em relação ao processo de avaliação, principalmente no que tange aos cursos de Administração do CEDERJ, é a necessidade do desenvolvimento e avaliação de habilidades profissionais demandadas pelos administradores em seu exercício cotidiano, quesitos em que, de acordo com os entrevistados, o modelo de avaliação da aprendizagem do CEDERJ deixa a desejar.

Em relação às avaliações, as APs visam estritamente à avaliação do conhecimento intelectual. Nas $\mathrm{ADs}$, muito raramente se avaliam habilidades mais interpessoais, e mesmo assim a elaboração e a coordenação dessas atividades ficam a cargo dos professores coordenadores das disciplinas, que possuem liberdade para decidir o que deve ser feito ou não.

Segundo os entrevistados, apesar dos bons resultados do Enade, realmente quem deve definir os melhores critérios de avaliação dos administradores formados pelo CEDERJ é o mercado de trabalho. Portanto, a exigência da implementação formal de mais atividades que visem ao desenvolvimento e à avaliação de habilidades profissionais é imprescindível.

Entre as atividades referidas, podem ser citadas a realização de dinâmicas de grupo e apresentação de trabalhos; a realização de palestras com empresários da localidade e até de alunos que desenvolvem atividades profissionais; a promoção de sessões de cinema visando à realização de debates; a organização de encontros, congressos e seminários na área de Administração, com total responsabilidade e preparação por parte dos alunos; a organização de rodadas de simulação de entrevistas de emprego e de visitas técnicas e 
rodadas de negociação; o incentivo à criação de empresas juniores; a organização de feiras de empregos, nas quais são convidadas empresas da região para se integrar aos alunos formandos, entre outras.

\section{Considerações finais}

A partir da proposta do trabalho e da análise comparativa efetuada, pôde-se constatar que o modelo de gestão da avaliação da aprendizagem utilizado pelo CEDERJ efetivamente se enquadra nas recomendações dos Referenciais de Qualidade utilizados como base para o trabalho. Apesar de haver total aderência aos referenciais propostos para análise, algumas recomendações podem ser efetuadas visando à melhoria do modelo proposto. Entre elas, podem ser citadas as seguintes:

- As avaliações do CEDERJ devem assumir caráter mais formativo;

- Deve ser estimulada pela coordenação geral do CEDERJ a realização de avaliações presenciais que visem medir não só o desempenho intelectual do aluno, mas também a performance do mesmo em relação à comunicação e relacionamento interpessoal;

- Deve haver maior preocupação, por parte do CEDERJ, em relação ao desenvolvimento de ha- bilidades profissionais práticas, de modo a preparar melhor o aluno para o mercado de trabalho.

É importante ressaltar que o presente trabalho se deteve em analisar o processo de gestão da avaliação da aprendizagem utilizado pelo CEDERJ especificamente no curso de Administração do Polo de Itaperuna. Portanto, foi identificado como resultado da pesquisa que os tutores coordenadores e tutores presenciais dos cursos de Administração do CEDERJ em seus diversos polos possuem autonomia em relação à proposição de atividades presenciais para os alunos, atividades essas que não fazem parte do processo de avaliação, mas podem ser complementares à formação do aluno como profissional.

Em função da complexidade do modelo educacional utilizado pelo CEDERJ, sugere-se como proposta a realização de uma ação mais abrangente envolvendo outros cursos e os seus respectivos coordenadores gerais, tutores, professores coordenadores e, principalmente, os alunos.

Finalmente, espera-se que este trabalho contribua com o desenvolvimento da EaD no país, fornecendo subsídios para que gestores de instituições, tanto públicas como privadas, possam se balizar pelos fatores de sucesso utilizados neste modelo para direcionar suas ações relacionadas à implementação $e$ gestão de seus programas baseados na EaD.

\section{Referências}

BARBOSA, J. R. A. A avaliação da aprendizagem como processo interativo: um desafio para o educador. Democratizar, v. 2, n. 1, jan./ abr. 2008.

BARDIN, L. Análise de conteúdo. Lisboa: Edições 70; 1977.

BLOOM, B. S., HASTINGS, J. T., MANDAUS, J. F. Manual de avaliação formativa e somativa do aprendizado escolar. São Paulo: Pioneira, 1983.

BRAGANÇA, R. C. M. Um modelo de avaliação. Universidade Federal Fluminense - UFF, 2010. Disponível em: <http://www.lanteuff.org>. Acesso em 26 nov. 2010.

BRASIL. MEC. Referenciais de Qualidade para Educação Superior a Distância. Brasília, 2007. Disponível em: <http://portal.mec.gov.br/seed/arquivos/pdf/referenciaisead.pdf> . Acesso em 08 out. 2010. 
CARNEIRO, O. T. e SANTOS, N. V. B. As contribuições da gestão de processos para a eficiência e eficácia do departamento de gestão de pessoas de uma empresa do setor sucoalcooleiro do interior de Minas Gerais. Fazu em Revista, Uberaba, n. 6, p. 121-192, 2009. Disponível em: <http://www.fazu.br/ojs/index.php/fazuemrevista/ article/viewArticle/28>. Acesso em 29 nov. 2010.

CARVALHO, R. S. Sistemas de gestão da aprendizagem e sistemas de gestão acadêmica: avaliados pela ótica do docente. Dissertação de mestrado profissional. Universidade Federal de Pernambuco. RecifePE, 2010. Disponível em: <http://pt.scribd.com/doc/34087396/Dissertacao-Pratica-Docente-e-os-Sistemas-deGestao-Academica-e-Gestao-da-Aprendizagem >. Acesso em 04 mar. 2011.

CAMPOS, F. C. A.; COSTA, R. M. E.; SANTOS, N. Fundamentos da Educação a Distância, mídias e ambientes virtuais. Juiz de Fora: Editar, 2007.

CEDERJ - Fundação Centro de Ciências e Educação Superior a Distância do Estado do Rio de Janeiro. Sobre o CEDERJ. Disponível em: <http://www.cederj.edu.br>. Acesso em: 02 set. 2013.

GUSSO, S. F. K. O tutor: professor e a avaliação da aprendizagem no ensino a distância. Ensaios Pedagógicos: Revista Eletrônica do Curso de Pedagogia das Faculdades OPET, n. 2, ago. 2009. Disponível em: <www.opet.com.br/revista/pedagogia/edicao.n2.asp>. Acesso em jul. 2013.

LIBÂNEO, J. C. Didática. São Paulo: Cortez, 1994.

MALHOTRA, N. K. Pesquisa de marketing: uma orientação aplicada. 4. ed. Porto Alegre: Bookman, 2006. MORAN, J. O Que é Educação a Distância. 2008. Disponível em: < http://www.eca.usp.br/prof/moran/dist. htm>. Acesso em 18 ago. 2008.

MORETTO, V. P. Planejamento: planejando a educação para o desenvolvimento de competências. 2. Ed. Petrópolis: Vozes, 2008.

PETERS, O. Didática do ensino a distância. São Leopoldo: Editora Unisinos, 2006.

QUINTANA, A. C.; QUINTANA, C. G. A execução das tarefas virtuais no contexto da Educação a Distância: um estudo em um curso de graduação em administração. Revista Gestão Universitária na América Latina GUAL, v. 5, n. 2, p. 277-297, ago. 2012.

SILVA, D. F. A. Modelo de maturidade de processos de gestão acadêmica em instituições privadas de Ensino Superior. Dissertação de Mestrado, Centro Estadual de Educação Tecnológica Paula e Souza. São Paulo, 2009. Disponível em: <http://www.centropaulasouza.sp.gov.br/Posgraduacao/Trabalhos/Dissertacoes/ DM_Tecn_daniel_fernando_antonucci_e_silva.pdf >. Acesso em 06 mar. 2011.

SINDER, M. Avaliação da aprendizagem e institucional. Universidade Federal Fluminense - UFF, 2010. Disponível em: http://www.lanteuff.org Acesso em 20 nov. 2010.

VERGARA, S. C. Métodos de pesquisa em Administração. São Paulo: Atlas, 2005.

TARDIFF, Maurice; LESSARD, Claude. O trabalho docente - elementos para uma teoria da docência como profissão de interações humanas. Petrópolis: Vozes, 2008. 